\title{
Smoking prevalence in England is below $20 \%$ for the first time in 80 years
}

A recent BMJ clinical review provided a useful and timely update on smoking cessation ${ }^{1} \mathrm{We}$ thought it would be useful to expand on the section of the review on 'Who smokes' by sharing the latest findings on smoking prevalence in England from a large national surveillance study which has been tracking smoking prevalence since $2006 .{ }^{2}$ Each month a new sample of approximately 1800 individuals aged $\geq 16$ are selected using a form of random location sampling and complete a computer-assisted household survey with a trained interviewer. Prevalence data are weighted to match English census data on age, sex, and socioeconomic group. The methods have been shown to result in a sample that is nationally representative in its socio-demographic composition and proportion of smokers as compared with other large national surveys such as Health Survey for England. ${ }^{2}$ An advantage of the Smoking Toolkit Study is that the data are available within weeks of collection and published online at www.smokinginengland.info.

For the first time in probably 80 years, England has seen smoking prevalence fall below $20 \%$. In 2013, 22,167 adults were surveyed. The prevalence of cigarette smoking was $19.3 \%$ (95\%CI 18.8 to 19.8$)$. Smoking was rare at the start of the $20^{\text {th }}$ century but increased relentlessly until the publication of 'Smoking and Health' in 1962 by which stage over $70 \%$ of men and $40 \%$ of women smoked. ${ }^{3}$

The decline in prevalence started in the 1970s and since then has averaged $0.6 \%$ per year; in 2013 it was slightly above this at $0.8 \%$ (www.smokinginengland.info). There is much still to be done, particularly on the social gradient in smoking, which contributes substantially to health inequalities. ${ }^{4}$ However, we hope that breaking the $20 \%$ barrier will motivate smoking 
cessation efforts across the country, including making more use of our stop-smoking services..$^{5}$

\section{References}

1. Zwar NA, Mendelsohn CP, Richmond RL. Supporting smoking cessation. BMJ 2014;348.

2. Fidler JA, Shahab L, West O, et al. 'The smoking toolkit study': a national study of smoking and smoking cessation in England. BMC Public Health 2011;11:479.

3. Royal College of Physicians. Fifty years since Smoking and health. Progress, lessons and priorities for a smoke-free UK. Report of conference proceedings. London: RCP, 2012.

4. Gruer L, Hart CL, Gordon DS, et al. Effect of tobacco smoking on survival of men and women by social position: a 28 year cohort study. BMJ 2009;338.

5. West R, May S, West M, et al. Performance of English stop smoking services in first 10 years: analysis of service monitoring data. BMJ 2013;347.

\section{Competing interests}

JB's post is funded by a fellowship from the UK Society for the Study of Addiction; RW is funded by Cancer Research UK; Cancer Research UK, the Department of Health, Pfizer, GlaxoSmithKline and Johnson and Johnson have all funded data collection for the Smoking Toolkit Study; JB has received an unrestricted research grant from Pfizer; RW undertakes research and consultancy and receives fees for speaking from companies that develop and manufacture smoking cessation medications (Pfizer, J\&J, McNeil, GSK, Nabi, Novartis, and Sanofi-Aventis), he also has a share of a patent for a novel nicotine delivery device. There are 
no other financial relationships with any organisations that might have an interest in the submitted work. 